\title{
Resveratrol protects against L-arginine-induced acute necrotizing pancreatitis in mice by enhancing SIRT1-mediated deacetylation of p53 and heat shock factor 1
}

\author{
NIAN WANG, FEN ZHANG, LIU YANG, JIANG ZOU, HAO WANG, KE LIU, MEIDONG LIU, \\ HUALI ZHANG, XIANZHONG XIAO and KANGKAI WANG \\ Translational Medicine Center of Sepsis, Department of Pathophysiology, Xiangya School of Medicine, \\ Central South University, Changsha, Hunan 410078, P.R. China
}

Received February 20, 2017; Accepted May 31, 2017

DOI: $10.3892 /$ ijmm.2017.3012

\begin{abstract}
Acute necrotizing pancreatitis (ANP) is a common severe critical illness with a high mortality rate. Resveratrol, a polyphenol compound derived from various plants such as grape skin, peanut, berry and veratrum, exhibits multiple biological activities, especially potent anti-inflammatory activity, but its effect on ANP has not yet been fully elucidated. The present study aimed to investigate the effects of resveratrol on L-arginine-induced ANP and the possible mechanisms. A mouse model of ANP was established by 2 hourly intraperitoneal injections of $8 \%$ L-arginine $(4 \mathrm{~g} / \mathrm{kg})$. Then the mice were treated by intragastric administration of resveratrol $(80 \mathrm{mg} / \mathrm{kg})$ every $12 \mathrm{~h}$ immediately after the second injection of L-arginine. Mice with ANP showed increased apoptosis of pancreatic acinar cells, pancreatic myeloperoxidase activity, serum lactate dehydrogenase activity, amylase, tumor necrosis factor- $\alpha$ (TNF- $\alpha$ ), interleukin-6 (IL-6) levels as well as decreased serum IL-10 level, pancreatic expression of heat shock factor 1 (HSF1), sirtuin 1 (SIRT1) and p53, but the ratio of acetylated HSF1 and p53 was markedly increased. Resveratrol enhanced the survival rate of mice with ANP from 47.8 to $71.4 \%$ and obviously restored the changes in mice with ANP as mentioned above. Additionally, interactions between SIRT1 and p53 and between SIRT1 and HSF1 in the pancreas of the mice were confirmed by co-immunoprecipitation. These data suggest that resveratrol protects against L-arginineinduced ANP, which may be related to the enhancement of SIRT1-mediated deacetylation of p53 and HSF1.
\end{abstract}

Correspondence to: Professor Kangkai Wang, Translational Medicine Center of Sepsis, Department of Pathophysiology, Xiangya School of Medicine, Central South University, 110 Xiangya Road, Changsha, Hunan 410078, P.R. China

E-mail: kangkaiwang@126.com

Key words: acute necrotizing pancreatitis, resveratrol, sirtuin 1, $\mathrm{p} 53$, heat shock factor 1 , deacetylation

\section{Introduction}

Acute pancreatitis (AP) is a trypsin-activated sudden inflammatory response in the pancreas and autodigestion of the pancreas caused by various etiological factors such as gallstones, craputence, hyperlipemia, virus, sepsis and shock $(1,2)$. Currently, AP is divided the mild AP, moderately severe AP (MSAP) and severe AP (SAP) in the clinic according to disease severity and prognosis (3). SAP is also called acute necrotizing pancreatitis (ANP) and generally manifests as diffuse pancreatic necrosis and hemorrhage, adiponecrosis, neutrophil and monocyte infiltration, necrosis and apoptosis of pancreatic acinar cells. It can rapidly develop into systemic inflammation and even multiple organ dysfunction syndrome (MODS), accompanied by an unacceptably high mortality rate. However, the therapy of ANP is now limited to symptomatic and supportive treatments such as analgesia, spasmolysis, improvement in microcirculation, antishock, antiinflammation and antiemetic. Yet up to $30 \%$ of ANP patients die from various complications (4). Therefore, searching for effective therapeutic targets and drugs are of great importance.

Today the pathogenesis of ANP has not been fully elucidated. It has been confirmed that the autodigestion of the pancreas by intrapancreatic trypsin, excessive inflammation, necrosis and apoptosis of pancreatic acinar cells may all be involved in this process (5-7). However, the use of trypsin inhibitors and antiinflammatory therapy directed at a certain inflammatory factor are usually noneffective in the treatment of ANP. The occurrence and development of ANP can be described as progression from an initial injury of pancreatic acinar cells to local and systemic inflammation (5). Uncontrolled release of a large amount of various inflammatory factors including tumor necrosis factor- $\alpha$ (TNF- $\alpha$ ), interleukin-6 (IL-6), IL-1 $\beta$ and IL-10, are not only the initial factors of ANP, but also promote the necrosis and apoptosis of pancreatic acinar cells and eventually aggravate the impairment of the pancreas in ANP (6). Hence, the decrease in the uncontrolled release of various inflammatory factors may be helpful to improve the prognosis of AP.

Resveratrol, a polyphenol compound derived from various plants such as grape skin, peanut, berry and veratrum has multiple biological activities, including potent anti-inflammatory 
activity, antioxidant, anti-aging, insulin sensitization and cardiac protection. It has been shown that resveratrol has certain protective effect on cerulein-induced acute edema pancreatitis and $4 \%$ sodium taurocholate-induced SAP as well as related complications in rats, but its effect on L-arginine-induced ANP remains unknown to date $(8,9)$. Resveratrol has been found to be an activator of sirtuin 1 (SIRT1). SIRT1 is one of the seven mammalian orthologs of the yeast protein silent information regulator 2 (Sir2), a conserved NAD-dependent protein deacetylase that plays an important role in the cell proliferation, differentiation, apoptosis, metabolism and inflammatory response through deacetylating certain lysine residues in a variety of downstream substrates including histone H3, p53, heat shock factor 1 (HSF1), and further enhancing their transcription activity (10-12). However, the role of SIRT1 in the development of ANP is largely unknown.

In this study, for the first time, to the best of our knowledge, the effect of resveratrol on L-arginine-induce ANP in mice was investigated, and whether the activation of SIRT1 and its deacetylation of downstream substrates are involved in this process was determined.

\section{Materials and methods}

Animals. Male Balb/c mice weighed 20-25 g were purchased from the Center of Experimental Animals in Central South University of China. All mice were kept on a 12-h light/dark cycle at a room temperature of $23 \pm 2^{\circ} \mathrm{C}$ and a relative humidity of $50 \pm 5 \%$ and housed individually with free access to food and water throughout the experiment. Mice were randomly assigned to the experimental procedures described as follows. Animal use procedures were approved by the Animal Welfare Ethics Committee of Central South University.

Establishment of a mouse model of acute pancreatitis and treatment. A mouse model of acute pancreatitis was established by 2 hourly intraperitoneal injections of $8 \%$ L-arginine hydrochloride ( $\mathrm{pH} 7.0,4 \mathrm{~g} / \mathrm{kg}$ body weight). The mice were randomly divided into three groups: control group (Con), L-arginine exposure group (AP), L-arginine and resveratrol treatment group (AP+RSV). Mice in the AP+RSV group were treated with intragastric administration of $80 \mathrm{mg} / \mathrm{kg}$ resveratrol every $12 \mathrm{~h}$ immediately after the second injection of L-arginine. Mice in the Con group and AP group were treated with the same volume of vehicle. Resveratrol was dissolved in $0.5 \%$ sodium carboxymethyl cellulose away from light and was used immediately after it was ready. Before administration of L-arginine, the mice were deprived of food and received only water for 10-12 h. After the first injection of L-arginine, the mice were given food and water ad libitum immediately and then sacrificed at 48 and $72 \mathrm{~h}$ after the second injection of L-arginine.

Reagents. The antibodies to HSF1 (1:2,000 dilution; 12972S), acetylated-lysine (1:1,000 dilution; 9441S), SIRT1 (1:2,000 dilution; 9475S) and p53 (1:1,000 dilution; 2524S) were purchased from Cell Signaling Technology, Inc. (Danvers, MA, USA). The antibody to glyceraldehyde 3-phosphate dehydrogenase (GAPDH; 1:3,000 dilution; G9545), resveratrol, L-arginine hydrochloride, sodium carboxymethyl cellulose, protease inhibitor cocktail were purchased from
Sigma-Adrich (St. Louis, MO, USA). Mouse TNF- $\alpha$, IL-6 and IL-10 enzyme-linked immunosorbent assay (ELISA) kits and IgG horseradish peroxidase-conjugated secondary antibody (1:10,000 dilution; BA1050, BA1054) were purchased from Boster Biological Technology, Ltd. (Wuhan, China). Lactate dehydrogenase and myeloperoxidase (MPO) assay kit were purchased from Nanjing Jiancheng Biology Engineering Institute. In situ cell death detection kit was purchased from Roche Applied Sciences (Mannheim, Germany). PureProteome $^{\mathrm{TM}}$ Protein A and Protein G magnetic beads were purchased from Merck Millipore (Billerica, MA, USA). Other reagents were analytically pure.

Histological examination. Pancreatic tissues were rinsed and fixed in $4 \%$ paraformaldehyde (PFA) at $4^{\circ} \mathrm{C}$ overnight. The PFA-treated pancreatic tissues were then processed with sequential clearing and dehydrating steps, and embedded in paraffin blocks. Samples were sectioned into $5-\mu \mathrm{m}$ slices and subjected to standard hematoxylin and eosin (H\&E) staining for the evaluation of pancreatic tissue injury. Images were taken under an optical microscope (Olympus, Tokyo, Japan). The severity of pancreatic tissue lesions was evaluated and scored by two experienced pathologists in a random and double-blinded manner according to a modified Grewal method as follows (13): edema was scored from 0-4 points (0, none; 1 , patchy interlobular septum; 2 , diffuse interlobular septum; 3, diffuse interlobular and intraacinar septum; 4 , diffuse intercellular space); leukocytic infiltration was scored from 0-4 points (0.5, per 5 leukocytes, $4,>30$ leukocytes); the percentage of acinar cell necrosis was evaluated by Image J software and scored from $0-4$ points ( 0 , none; $1,1-10 \%$ necrosis area; 2, 11-20\% necrosis area; 3, 21-30\% necrosis area; $4,>30 \%$ necrosis area) and hemorrhage was scored from $0-1$ points $(0$, none; 1 , hemorrhage).

Measurement of serological index. Blood was obtained by direct cardiac puncture under deep anesthesia at $48 \mathrm{~h}$ and $72 \mathrm{~h}$ after the second injection of L-arginine and clotted at room temperature for $4 \mathrm{~h}$. To obtain serum samples, the blood was centrifuged at $1,500 \mathrm{x} g$ for $10 \mathrm{~min}$. The serum amylase level was further detected at the clinical laboratory of Xiangya Hospital. ELISA assays were performed to detect the TNF- $\alpha$, IL-1 $\beta$, IL- 6 and IL-10 contents in the serum according to the manufacturer's protocol. Serum lactate dehydrogenase (LDH) activity was measured by a colorimetric method according to the manufacturer's protocol.

MPO activity assay. The pancreatic MPO activity was assessed by an MPO colorimetric activity assay kit according to the manufacturer's protocol and presented as units per milligram of pancreatic tissue.

Terminal deoxynucleotidyltransferase-mediated dUTP nick end labeling (TUNEL) assay. TUNEL staining was performed to detect the apoptosis of pancreatic acinar cells through in situ cell apoptosis detection kits according to the manufacturer's instructions. Pancreatic tissues were rinsed and fixed in $4 \%$ PFA at $4^{\circ} \mathrm{C}$ overnight followed by paraffin embedding. Paraffin-embedded sections of the samples were deparaffinated and hydrated using graded ethanol, and then incubated 
in $20 \mathrm{~g} / \mathrm{ml}$ protease $\mathrm{K}$ at $37^{\circ} \mathrm{C}$ for $30 \mathrm{~min}$. After being washed with phosphate-buffered saline (PBS) for 5 min three times, the samples were incubated with $0.1 \%$ Triton X-100 for $20 \mathrm{~min}$ at room temperature and then washed with PBS for 5 min three times. Terminal deoxynucleotidyl transformerase (TDT) and dUTP were mixed at a 2:29 ratio and then added to the sample and incubated at $37^{\circ} \mathrm{C}$ for $2 \mathrm{~h}$. After washing with PBS for 5 min three times, the sections were immersed into $3 \% \mathrm{H}_{2} \mathrm{O}_{2}$ prepared by methanol for $15 \mathrm{~min}$ away from light, and then covered with converter-POD at $37^{\circ} \mathrm{C}$ for $30 \mathrm{~min}$ in a humidified box. After rinsing, the samples were incubated with DAB substrate kit under a light microscope. The slides were lightly counterstained with haematoxylin and then dehydrated and mounted. For each pancreas specimen, tissue sections were examined under a light microscope at x100 and x200 magnifications. Ten random fields per section were counted and analyzed by Image Pro-Plus 7.0 software and the percentage of apoptotic cells was finally calculated as the apoptotic index.

Quantitative (real-time) polymerase chain reaction. Total RNA of the pancreatic tissues was extracted by TRIzol and reverse transcribed to cDNA with Primescript ${ }^{\mathrm{TM}} \mathrm{RT}$ reagent kit with gDNA Eraser according to the manufacturer's instructions (Takara Shuzo Co., Kyoto, Japan). The concentration and purity of total RNA were determined by measuring the OD260 and OD260/OD280 ratio, respectively. The mRNAs of TNF- $\alpha$, IL- 6 and IL-10 were measured by SYBR Premix Ex Taq ${ }^{\mathrm{TM}}$ (Takara Shuzo Co.) through an ABI 7500 real-time PCR system (Life Technology Corp., Carsbad, CA, USA). Each cDNA sample was analyzed in triplicate. The relative quantitation of mRNA was analyzed using the equation: ratio $=2^{-\Delta \Delta \mathrm{Ct}}$ and normalized to GAPDH. The following primers synthesized by Sangon Biotech Co., Ltd. (Shanghai, China) were used: TNF- $\alpha$ forward, 5'-ACCCTCACACTCACAAA CCA-3' and reverse, 5'-ACAAGGTACAACCCATCGGC-3'; IL-6 forward, 5'-CCCCAATTTCCAATGCTCTCC-3' and reverse, 5'-CGCACTAGGTTTGCCGAGTA-3'; IL-10 forward, 5'-GCTCTTGCACTACCAAAGCC-3' and reverse, 5'-CTGC TGATCCTCATGCCAGT-3'; GAPDH forward, 5'-GGGTCC CAGCTTAGGTTCAT-3' and reverse, 5'-TACGGCCAAATC CGTTCACA-3'.

Western blotting. Mouse pancreatic tissue (100 mg) was homogenized in $0.5 \mathrm{ml}$ lysate buffer containing $20 \mathrm{mM}$ Tris- $\mathrm{HCl}$ (pH 7.4), $5 \mathrm{mM}$ EDTA, $100 \mathrm{mM} \mathrm{Na} \mathrm{P}_{2} \mathrm{O}_{7}, 2 \mathrm{mM}$ $\mathrm{Na}_{3} \mathrm{VO}_{4}, 100 \mathrm{mM} \mathrm{NaF}$ and $1 \%$ Nonidet P-40 and protease inhibitors were added at a fixed volume ratio [lysate buffer:phenylmethylsulfonyl fluoride (PMSF):protease inhibitor cocktail, 100:1:1]. Homogenized samples were centrifuged at $4^{\circ} \mathrm{C}$, at $14,000 \mathrm{rpm}$ for $15 \mathrm{~min}$. The concentrations of protein from the supernatant were determined using BCA protein assay reagent. Protein $(25 \mu \mathrm{g})$ was loaded for $10 \%$ sodium dodecyl sulfate-polyacrylamide-gel electrophoresis (SDS-PAGE) and then transferred to polyvinylidene difluoride (PVDF) membranes (Merck Millipore). After blocking with $5 \%$ bovine serum albumin, immunoblotting was carried out with various primary antibodies at $4^{\circ} \mathrm{C}$ overnight or at $25^{\circ} \mathrm{C}$ for $2 \mathrm{~h}$ (anti-GAPDH antibody was used as an internal control). After incubation with IgG horseradish peroxidase-conjugated secondary antibody at

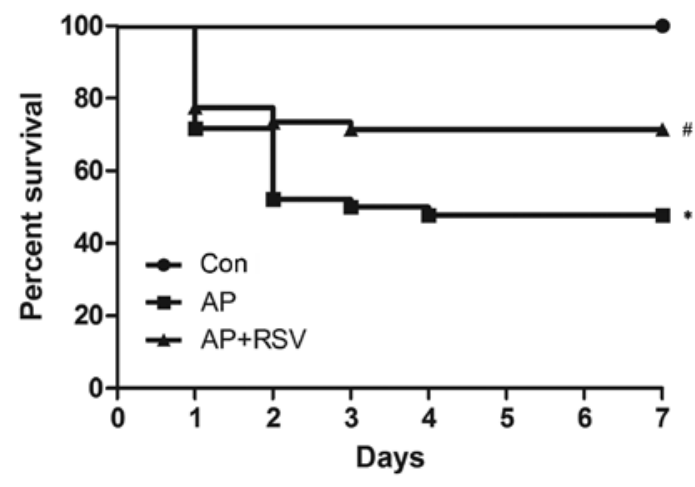

Figure 1. Effect of resveratrol on the survival of mice with L-arginineinduced acute necrotizing pancreatitis (ANP). The mice were randomly divided into three groups: Control group (Con, $n=20)$, L-arginine exposure group [acute pancreatitis (AP), $n=46$ ], L-arginine and resveratrol treatment group (AP+RSV, $n=49)$. Mice in the $A P+R S V$ group were treated with intragastric administration of $80 \mathrm{mg} / \mathrm{kg}$ resveratrol every $12 \mathrm{~h}$ immediately after the second injection of L-arginine. The mice in the Con group and AP group were treated with the same volume of $0.5 \%$ sodium carboxymethyl cellulose. The mice were kept and observed for 7 days after the first injection of L-arginine. Kaplan-Meyer method was used to compare the differences in the 7 -day survival rate between groups. ${ }^{*} \mathrm{p}<0.01$ vs. Con; ${ }^{\#} \mathrm{p}<0.05$ vs. AP.

room temperature for $1 \mathrm{~h}$, the membranes were washed three times successively. Then the specific proteins were detected by enhanced chemiluminescence (Invitrogen, Carlsbad, CA, USA) according to the manufacturer's instructions. The relative band intensity was quantified by Quantity One software (Bio-Rad Laboratories, Inc., Hercules, CA, USA).

Co-immunoprecipitation. Fresh mouse pancreatic tissue was rapidly homogenized in lysate buffer as mentioned above. The protein concentration was then adjusted to $3 \mu \mathrm{g} / \mu \mathrm{l}$ and $800 \mu \mathrm{g}$ total protein and $4 \mu \mathrm{g}$ capture antibody (SIRT1, HSF1 or p53) were incubated at $2-8^{\circ} \mathrm{C}$ with continuous mixing overnight. Fifty microliters of protein $\mathrm{A}$ and protein $\mathrm{G}$ magnetic beads was resuspended and washed with $500 \mu \mathrm{l}$ PBS containing $0.1 \%$ Tween-20. The reaction containing the pre-formed antibody-antigen complex mentioned above was subsequently added to the magnetic beads and incubated for $8 \mathrm{~h}$ at $2-8^{\circ} \mathrm{C}$ with continuous mixing to capture the immune complex. The magnetic beads were collected by putting the tube into the magnetic stand, allowing the beads to migrate to the magnet, and then removing the sample with a pipette. After washing the beads with $500 \mu \mathrm{l}$ PBS containing $0.1 \%$ Tween-20 for 3 times, $60 \mu 1$ of $5 \mathrm{X}$ sample loading buffer suitable for electrophoresis was added and mixed to resuspend the beads. The beads were heated at $70-90^{\circ} \mathrm{C}$ for $10 \mathrm{~min}$ and stored at $-80^{\circ} \mathrm{C}$ until being used for western blotting.

Acetylation assay. Fresh mouse pancreatic tissue was subjected to immunoprecipitation with mouse HSF1 and p53 antibodies, while acetylated HSF1 and p53 were detected by western blotting with an acetylated lysine antibody. Then the acetylation of HSF1 and p53 was evaluated by calculating the ratio of acetylated HSF1 and p53 to total HSF1 and p53, respectively.

Statistical analysis. All data were analyzed by SPSS 18.0 software. Measurement data are shown as mean \pm SEM of three different experiments and analyzed by unpaired two-tailed 
A
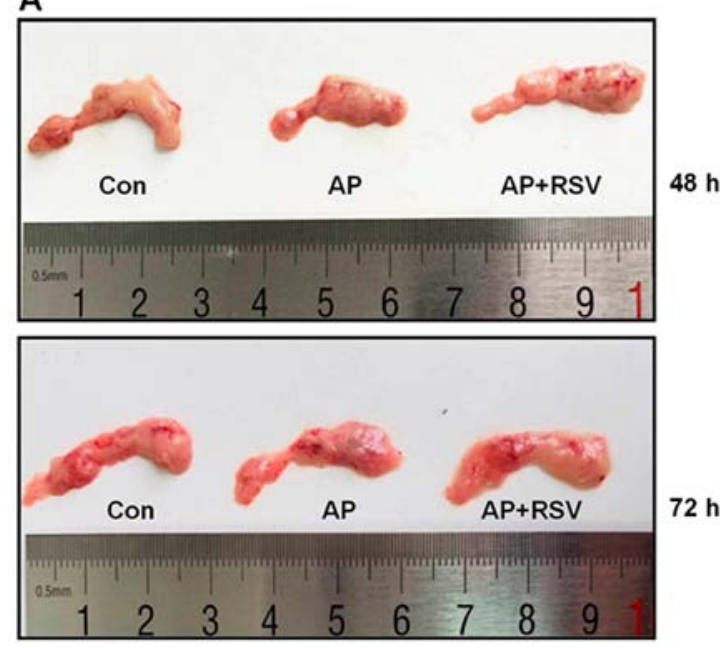

B
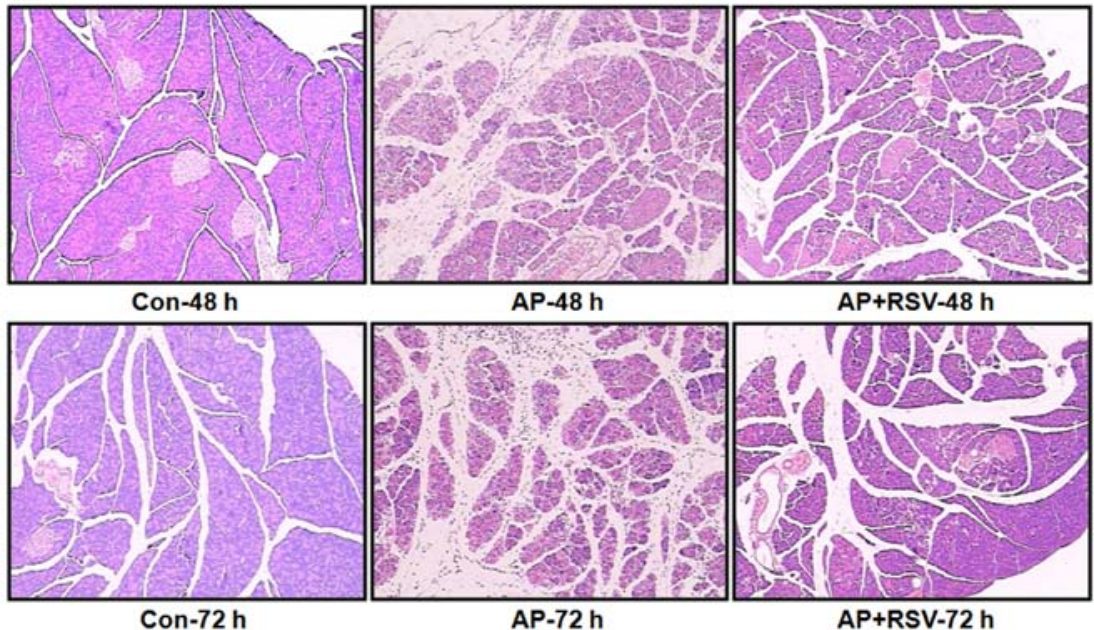

Con-72 h

AP-72 h

AP+RSV-72 h

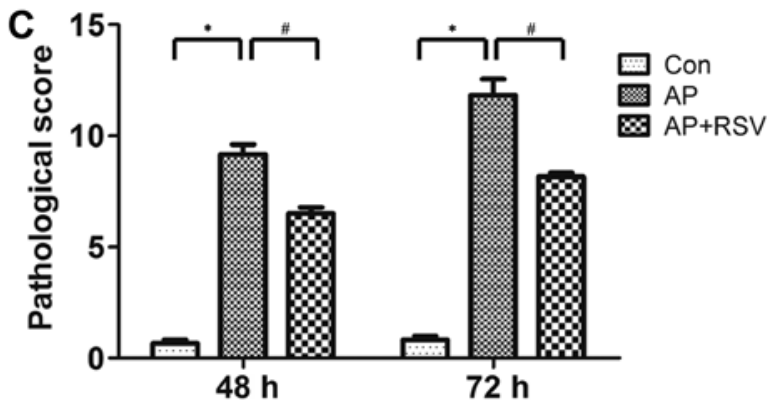

Figure 2. Effect of resveratrol on the pancreatic damage of mice with L-arginine-induced acute necrotizing pancreatitis (ANP). (A) General morphology of the pancreas. (B) H\&E-stained pancreatic sections (magnification, $\mathrm{x} 40$ ) and (C) pathological score of the pancreas at 48 and $72 \mathrm{~h}$ after the second injection of L-arginine. " p $<0.05$ vs. Con; ${ }^{*} \mathrm{p}<0.05$ vs. acute pancreatitis (AP) ( $=5$ ). Con, control group; AP, L-arginine exposure group; AP+RSV, L-arginine and resveratrol treatment group.

Student's t-tests. Kaplan-Meier analysis was performed to compare the differences in survival rate between different groups. $\mathrm{P}<0.05$ was considered statistically significant.

\section{Results}

Effect of resveratrol on the survival of mice with L-arginineinduced ANP. To assess the effect of resveratrol on the prognosis of ANP, a mouse model of ANP was established by intraperitoneal injection of L-arginine as reported previously $(14,15)$.
No mouse died in the control group; the 7-day survival rate was $100 \%$, while the 7-day survival rate of mice with ANP was obviously decreased to $47.8 \%$, which was significantly lower than that of the control group ( $<<0.05)$. In contrast, resveratrol enhanced the 7-day survival rate of mice with ANP to $71.4 \%$ $(\mathrm{p}<0.05)$ (Fig. 1).

Effect of resveratrol on the pancreatic morphology of mice with L-arginine-induced ANP. The mice treated with 2 hourly intraperitoneal injections of $8 \% \mathrm{~L}$-arginine hydrochloride 

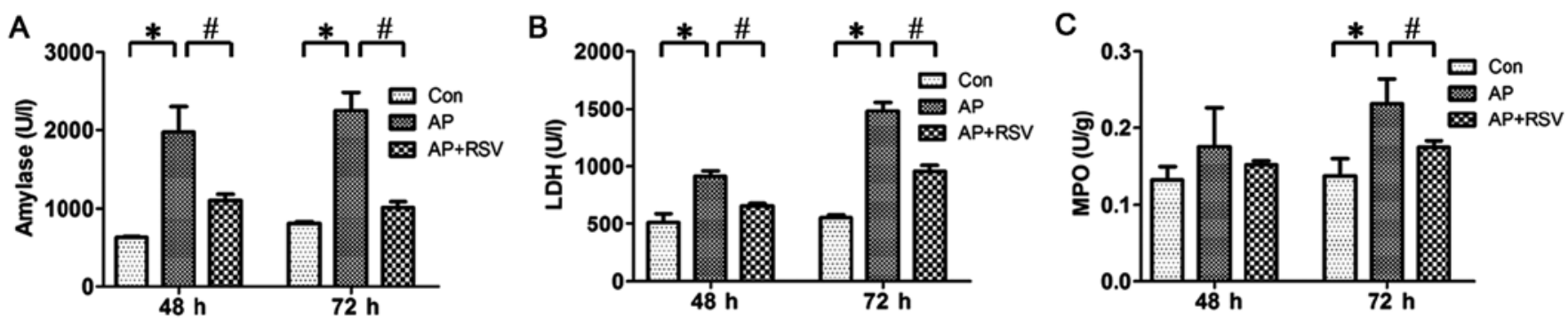

Figure 3. Effect of resveratrol on the serum amylase level, lactate dehydrogenase (LDH) activity and pancreatic myeloperoxidase (MPO) activity in mice with L-arginine-induced acute necrotizing pancreatitis (ANP). Serum amylase level (A), LDH activity (B) and pancreatic MPO activity (C) at 48 and $72 \mathrm{~h}$ after the second injection of L-arginine. ${ }^{*} \mathrm{p}<0.05$ vs. Con; ${ }^{*} \mathrm{p}<0.05$ vs. acute pancreatitis (AP) ( $\mathrm{n}=5$ ). Con, control group; AP, L-arginine exposure group; AP+RSV, $\mathrm{L}$-arginine and resveratrol treatment group.

developed ANP at $48 \mathrm{~h}$ after the second injection of L-arginine. As shown in Fig. 2A, the pancreas of the mice in the Con group was colored grey-white with normal structure, while the pancreas of the mice with ANP was colored gray-red with obvious roughness, necrosis and diffuse hemorrhage at $48 \mathrm{~h}$ and $72 \mathrm{~h}$ after the second injection of L-arginine. The pancreas in the resveratrol-treated mice with ANP showed a lighter color than that of the mice with ANP and minimal necrosis. The structure of the pancreas was close to that of the mice in the Con group.

H\&E staining showed wider pancreatic interlobular and acini septum, leukocyte infiltration, and up to a $20 \%$ necrotic area as well as hemorrhage in the mice with ANP at $48 \mathrm{~h}$ after the second injection of L-arginine, while pancreatic interlobular and acini septum, and intercellular space were all widened. A large amount of leukocyte infiltration and a $>30 \%$ necrotic area as well as hemorrhage were observed in the mice with ANP at $72 \mathrm{~h}$ after the second injection of L-arginine. However, the resveratrol-treated mice with ANP showed narrower pancreatic interlobular and acini septum, less leukocyte infiltration and a $<10 \%$ necrotic area (Fig. 2B). According to the modified Grewal method, the pancreatic damage was scored. The pathological scores of AP mice at $48 \mathrm{~h}$ and $72 \mathrm{~h}$ after the second injection of L-arginine were both significantly higher than those of the control group, while resveratrol obviously decreased the pathological scores of the mice with ANP (p<0.05) (Fig. 2C).

Effect of resveratrol on the serum amylase level, $L D H$ activity and pancreatic MPO activity of mice with L-arginine-induced $A N P$. As the serum amylase level is the most commonly used biochemical marker of AP, the serum LDH activity could reflect the degree of necrosis and MPO activity is related to neutrophil recruitment. Thus, in this study, the serum amylase level, LDH activity and pancreatic MPO activity were detected at 48 and $72 \mathrm{~h}$ after the second injection of L-arginine. The results showed that the serum amylase level, LDH activity and pancreatic MPO activity were significantly higher in the mice with ANP compared with these parameters of the mice in the Con group $(p<0.05)$. Resveratrol obviously decreased the serum amylase level, LDH activity and pancreatic MPO activity of the mice with ANP (p<0.05) (Fig. 3).

Effect of resveratrol on the apoptosis of pancreatic acinar cells in mice with L-arginine-induced ANP. The apoptosis of pancreatic acinar cells is also one of the typical characteristics of
ANP. TUNEL staining assay was used to detect the apoptosis of pancreatic acinar cells. Significant increases in the apoptotic index were observed in the mice with ANP $(18.33 \pm 3.51$ vs. $4.67 \pm 1.53$, $24.33 \pm 4.04$ vs. $4.33 \pm 1.53, \mathrm{p}<0.05)$ at 48 and $72 \mathrm{~h}$ after the second injection of L-arginine, while resveratrol obviously decreased the apoptotic index of the mice with ANP $(10 \pm 2$ vs. $18.33 \pm 3.51$, $16 \pm 2$ vs. $24.33 \pm 4.04$, p $<0.05)$ (Fig. 4).

Effect of resveratrol on pancreatic IL-6, TNF- $\alpha, I L-10 \mathrm{mRNA}$ expression and serum IL-6, TNF- $\alpha, I L-10$ levels of the mice with L-arginine-induced ANP. The development of ANP is considered as progression from the initial injury of exocrine pancreas to local and systemic inflammatory response (5). Therefore, the pancreatic IL-6, TNF- $\alpha$, IL-10 mRNA expression and serum IL- 6, TNF- $\alpha$, IL-10 levels were detected. It was found that the pancreatic IL- 6 , TNF- $\alpha$ mRNA expression and serum IL-6, TNF- $\alpha$ levels of mice with ANP were significantly increased compared with the mice in the Con group $(\mathrm{p}<0.05)$, while the pancreatic IL-10 mRNA expression and serum IL-10 level were obviously decreased $(\mathrm{p}<0.05)$. Resveratrol did not only markedly decrease the pancreatic IL-6, TNF- $\alpha$ mRNA expression and serum IL-6, TNF- $\alpha$ levels of mice with ANP but also enhanced the pancreatic IL-10 mRNA expression and serum IL-10 level (p<0.05) (Fig. 5).

Effect of resveratrol on the SIRT1 protein expression and activity in the pancreas of mice with L-arginine-induced $A N P$. Resveratrol has been confirmed as a classic SITR1 activator, but whether SIRT1 is involved in the pathogenesis of L-arginine-induced acute pancreatitis is still unknown. The expression and activity were further detected. It was shown that the expression of SIRT1 in the pancreas of mice with ANP was significantly decreased to $\sim 40 \%$ of that in the mice in the control group at 48 and $72 \mathrm{~h}$ after the second injection of L-arginine $(\mathrm{p}<0.05)$, but obviously increased SIRT1 expression was detected in the resveratrol-treated mice with ANP $(\mathrm{p}<0.05)$ (Fig. 6).

p53 is a pro-apoptotic protein, the deacetylation of which indirectly reflects the activity of SIRT1 $(5,16,17)$. Firstly, the expression of p53 was detected. p53 protein expression was significantly downregulated in the pancreas of the mice with ANP at $48 \mathrm{~h}$ and $72 \mathrm{~h}$ after the second injection of L-arginine $(\mathrm{p}<0.05)$, while resveratrol obviously upregulated the $\mathrm{p} 53$ protein expression of the mice with ANP $(\mathrm{p}<0.05)$. Co-immunoprecipitation assay showed that p53 was 

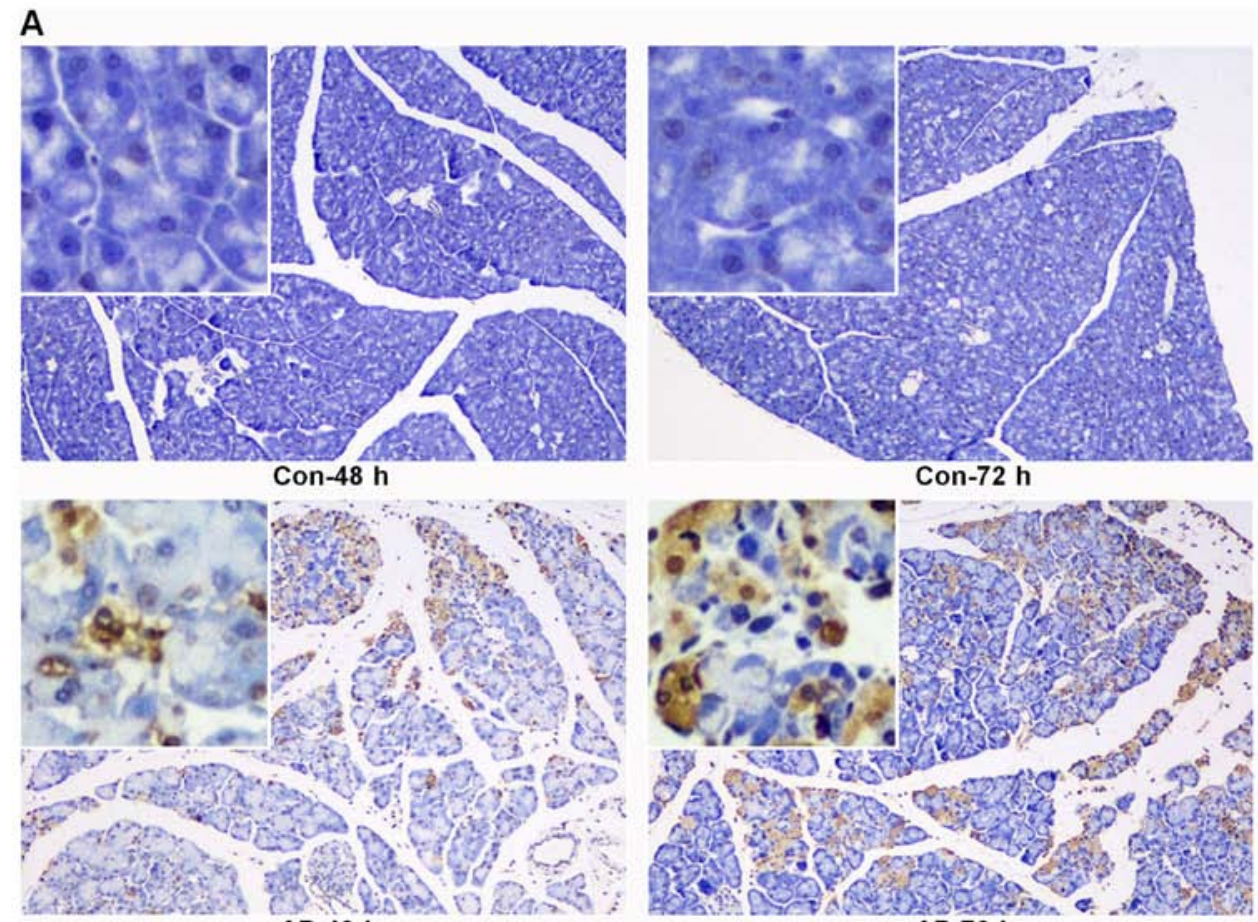

AP-48 h

AP-72 h

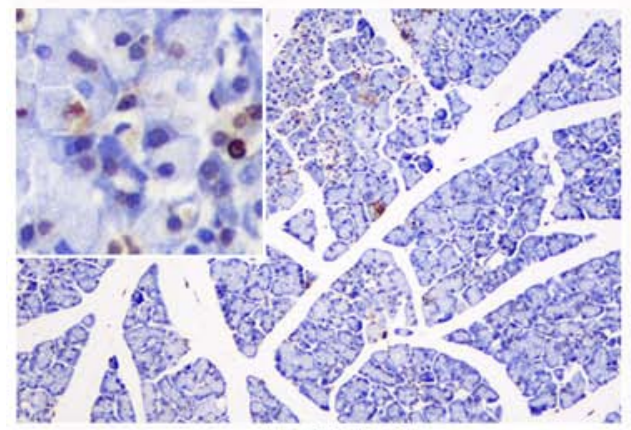

AP+RSV-48 h

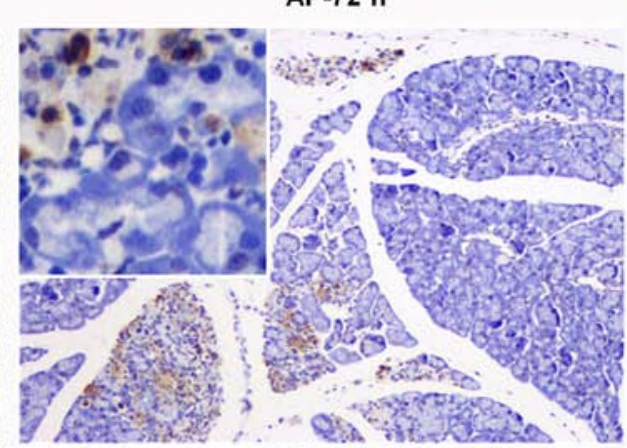

AP+RSV-72 h

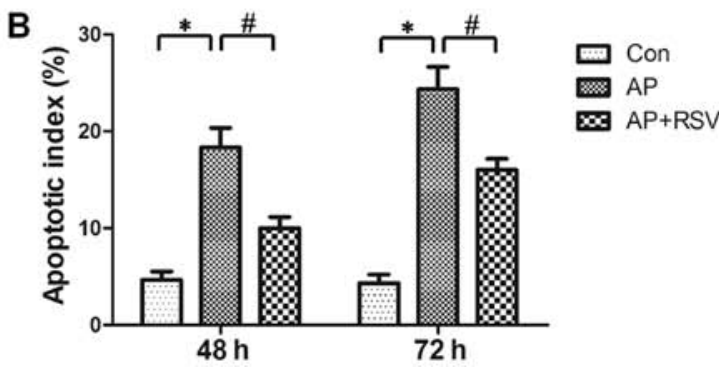

Figure 4. Effect of resveratrol on the apoptosis of pancreatic acinar cells in mice with L-arginine-induced acute necrotizing pancreatitis (ANP). Apoptotic pancreatic acinar cells were detected by terminal deoxynucleotidyl transferase-mediated dUTP nick end labeling (TUNEL) staining. TUNEL-positive cells are indicated by brown staining. Representative photomicrographs demonstrating TUNEL staining of pancreatic sections (A) and quantitative analysis of TUNEL-positive cells as the apoptotic index (B) are shown. ${ }^{*} \mathrm{p}<0.05$ vs. Con; ${ }^{*} \mathrm{p}<0.05$ vs. acute pancreatitis (AP) (n=5). Con, control group; AP, L-arginine exposure group; AP+RSV, L-arginine and resveratrol treatment group.

precipitated by the SIRT1 antibody and further acetylation assay showed that the ratio of acetylated p53 was markedly higher in the pancreas of the mice with ANP at $48 \mathrm{~h}$ and $72 \mathrm{~h}$ after the second injection of L-arginine $(\mathrm{p}<0.05)$, but resveratrol markedly attenuated the acetylation of p53 in the mice with ANP (p<0.05) (Fig. 7).

Effect of resveratrol on the expression and acetylation of HSF 1 in the pancreas of mice with L-arginine-induced $A N P$. HSF1 is a crucial transcription factor in heat shock response and also plays an important role in the inflammatory response and cell apoptosis. The activity of HSF1 is closely related to its acetylation. To investigate the role of HSF1 in the L-arginine-induced ANP, co-immunoprecipitation assay was firstly performed to detect the interation between HSF1 and SIRT1. HSF1 was precipitated by the SIRT1 antibody in the different groups, although the total expression of HSF1 was significantly decreased in the pancreas of the mice with ANP at 48 and $72 \mathrm{~h}$ after the second injection of L-arginine $(p<0.05)$. Acetylation assay showed that the ratio of acetylated 

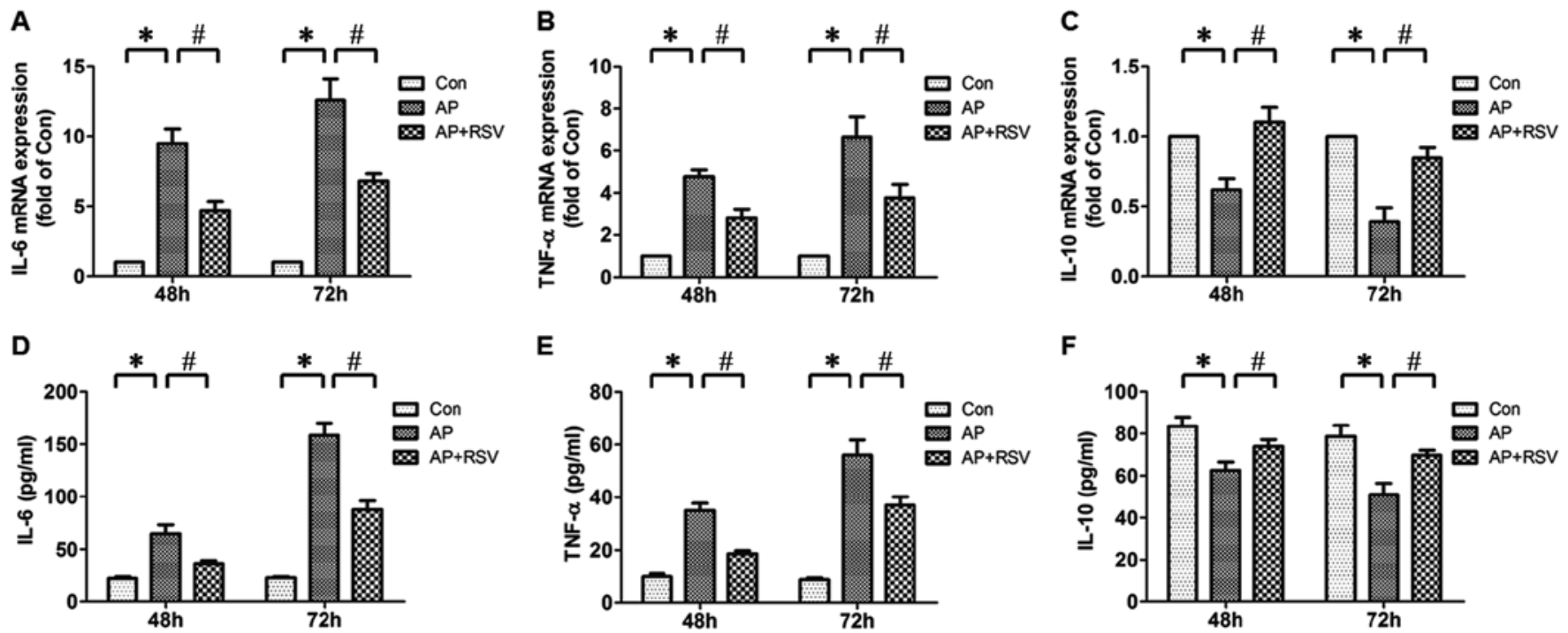

Figure 5. Effect of resveratrol on the pancreatic interleukin-6 (IL-6), tumor necrosis factor- $\alpha$ (TNF- $\alpha$ ), IL-10 mRNA expression levels and serum IL-6, TNF- $\alpha$, IL-10 levels in mice with L-arginine-induced acute necrotizing pancreatitis (ANP). Pancreatic IL-6 (A), TNF- $\alpha$ (B), IL-10 (C) mRNA expression levels were detected at $48 \mathrm{~h}$ and $72 \mathrm{~h}$ after the second injection of L-arginine by real-time PCR. Serum IL-6 (D), TNF- $\alpha$ (E) and IL-10 (F) levels were detected at $48 \mathrm{~h}$ and $72 \mathrm{~h}$ after the second injection of L-arginine by ELISA. The values are shown as means \pm SD. ${ }^{*} \mathrm{p}<0.05 \mathrm{vs}$. Con; ${ }^{*} \mathrm{p}<0.05$ vs. acute pancreatitis $(\mathrm{AP})(\mathrm{n}=5)$. Con, control group; AP, L-arginine exposure group; AP+RSV, L-arginine and resveratrol treatment group.
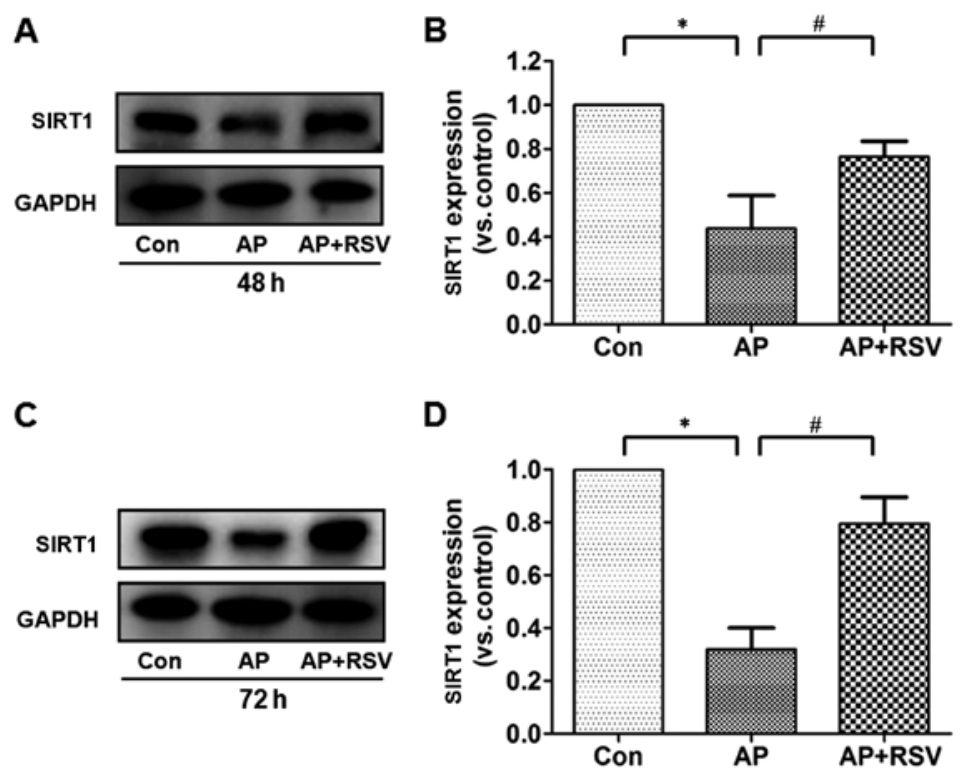

Figure 6. Effect of resveratrol on the sirtuin 1 (SIRT1) protein expression in the pancreas of mice with L-arginine-induced acute necrotizing pancreatitis (ANP). Western blotting was performed to detect the SIRT1 protein expression in the pancreas of mice with L-arginine-induced acute pancreatitis at $48 \mathrm{~h}(\mathrm{~A}$ and B), $72 \mathrm{~h}(\mathrm{C}$ and $\mathrm{D})$ after the second injection of $\mathrm{L}$-arginine. ${ }^{\mathrm{p}}<0.05$ vs. Con; ${ }^{\mathrm{p}} \mathrm{p}<0.05$ vs. acute pancreatitis $(\mathrm{AP})(\mathrm{n}=3)$. Con, control group; AP, L-arginine exposure group; AP+RSV, L-arginine and resveratrol treatment group.

HSF1 was significantly upregulated $(\mathrm{p}<0.05)$. However, resveratrol obviously enhanced the total expression of HSF1 but decreased the acetylation of HSF1 in the pancreas of the mice with ANP (p<0.05) (Fig. 8).

\section{Discussion}

AP, a common inflammatory disorder of the pancreas, has become the leading cause of admission to intensive care units (ICUs) worldwide (18). It has been confirmed that AP is initiated by the activation of various enzymes in pancreatic acinar cells, which leads to the injury of acinar cells, followed by the release of pro-inflammatory factors such as TNF- $\alpha$, IL-1 $\beta$ and IL-6 (19). The chemokines further released from the injured acinar cells then promote inflammatory cells including neutrophils and macrophages to accumulate in the pancreas, which results in exacerbating the local inflammatory response in the pancreas and progressing rapidly into a systemic inflammatory response (5). Under this condition, the excessive release of various inflammatory factors increases the microvessel density, induces thrombosis and hemorrhage and finally increases the apoptosis and necrosis of acinar cells. In 


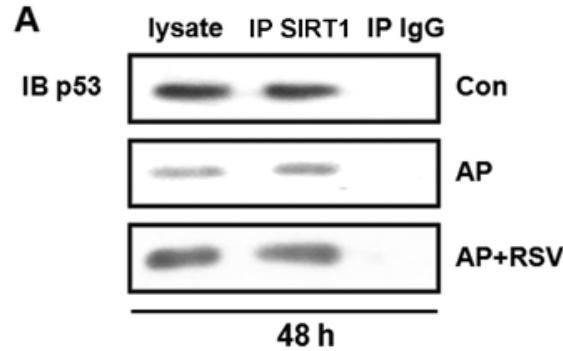

C

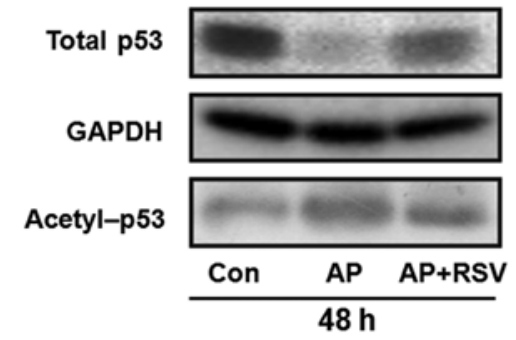

E

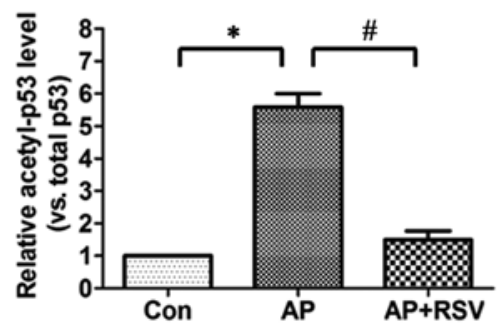

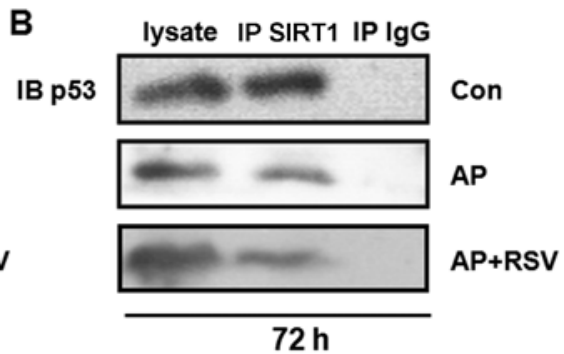

D

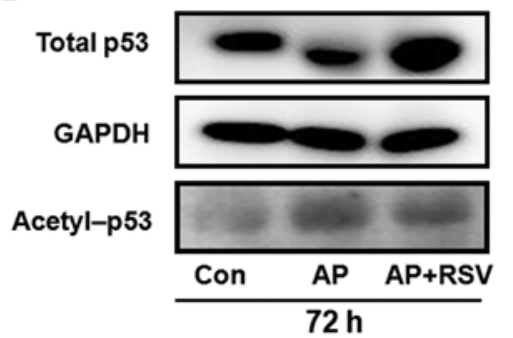

$\mathbf{F}$

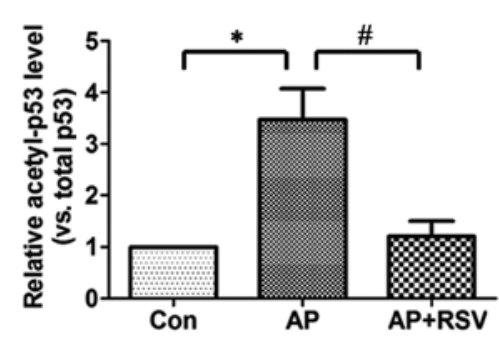

Figure 7. Effect of resveratrol on the $\mathrm{p} 53$ and acetylated p53 expression in the pancreas of mice with L-arginine-induced acute necrotizing pancreatitis (ANP). Interaction between sirtuin 1 (SIRT1) and p53 in the pancreas was detected by co-immunoprecipitation at $48 \mathrm{~h} \mathrm{(A),} 72 \mathrm{~h}$ (B) after the second injection of L-arginine. Expression levels of p53 and acetylated p53 in the pancreas were detected by immunoblotting at $48 \mathrm{~h}(\mathrm{C}$ and E), $72 \mathrm{~h}(\mathrm{D}$ and F) after the second injection of L-arginine. ${ }^{*} \mathrm{p}<0.05$ vs. Con; ${ }^{*} \mathrm{p}<0.05$ vs. acute pancreatitis (AP) $(\mathrm{n}=3)$. Con, control group; AP, L-arginine exposure group; AP+RSV, L-arginine and resveratrol treatment group.

addition, the gut barrier dysfunction is usually found in AP, which can result in bacterial translocation, further activate the macrophages to release a large quantity of inflammatory factors and induce a secondary attack to the pancreas $(20,21)$. Hence, controlling the rapidly progressive inflammatory response and inhibiting the injury of pancreatic acinar cells may be beneficial to improve the prognosis of ANP.

Resveratrol is a natural polyphenol compound mainly found in various plants and red wine. It is well known for its anti-inflammatory and antioxidant effects. It has been confirmed that resveratrol has protective effects on sodium taurocholate-induced ANP and cerulean-induced acute edema pancreatitis. L-arginine-induced experimental model of ANP was firstly reported by Tani et al (22), since L-arginine selectively destroys pancreatic acinar cells by inducing amino acid imbalance, decreasing the synthesis of polyamine, nucleic acid and proteinase and resulting in excessive activation of zymogen. In addition, L-arginine could induce the expression of different types of inflammatory factors and apoptosis-related genes and proteins in the pancreatic acinar cells. Compared with other invasive experimental models of ANP, the L-arginine-induced experimental model of ANP has the advantages of non-invasive, easier operation, higher success rate and lower cost, although the death rate is high. It is commonly used as an investigative tool for screening and developing effective therapies for ANP. In this study, the 7-day survival rate of the L-arginine-induced mice with
ANP was $47.8 \%$, while administration of 20 and $40 \mathrm{mg} / \mathrm{kg}$ resveratrol every $12 \mathrm{~h}$ immediately after the second injection of L-arginine had no significant effect on the survival of the mice with ANP (data not shown). However, administration of $80 \mathrm{mg} / \mathrm{kg}$ resveratrol significantly enhanced the 7-day survival rate of the mice with ANP to $71.4 \%$. Further studies showed that the L-arginine-induced ANP model was successfully established at $48 \mathrm{~h}$ after the second injection of $\mathrm{L}$-arginine, which was mainly manifested as pancreatic and systemic inflammation, apoptosis and necrosis of pancreatic acinar cells. Administration of $80 \mathrm{mg} / \mathrm{kg}$ resveratrol every $12 \mathrm{~h}$ immediately after the second injection of L-arginine markedly ameliorated L-arginine-induced pancreatic inflammation and injury as well as systemic inflammation. These results proved that resveratrol could protect L-arginine-induced ANP through alleviating the pancreatic inflammatory response.

In recent years, accumulating evidence suggests that the biological activities of resveratrol are closely related to the activation of SIRT1. SIRT1 has been proven to be involved in a variety of cellular functions, such as proliferation, differentiation, apoptosis, aging and metabolism. It also participates in the regulation of inflammation, but its role in ANP is poorly understood to date. Our data showed that the pancreatic expression of SIRT1 in L-arginine-induced mice with ANP was significantly decreased compared with that in the normal mice, which was reversed by resveratrol treatment. The activation of SIRT1 enhances the transcriptional activities 
A

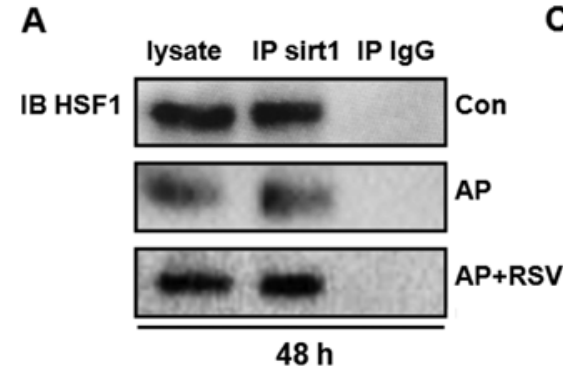

B

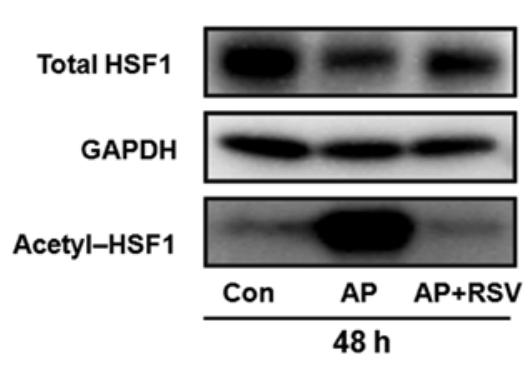

E

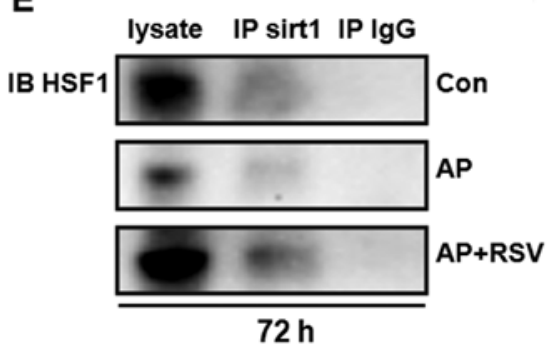

$\mathbf{F}$

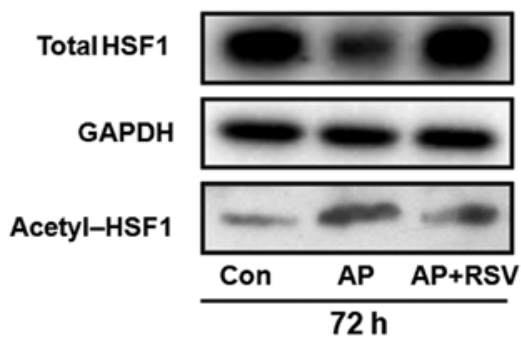

C

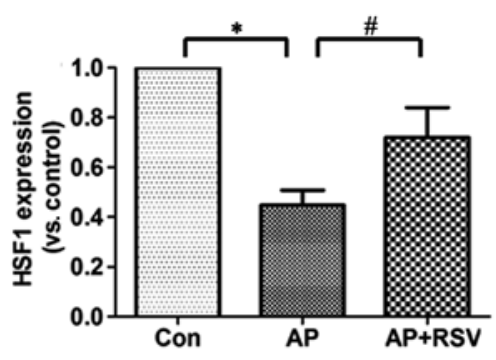

D

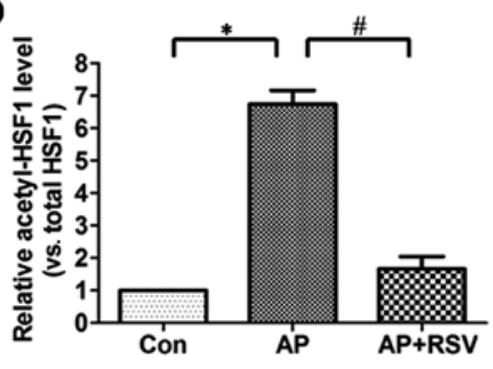

G

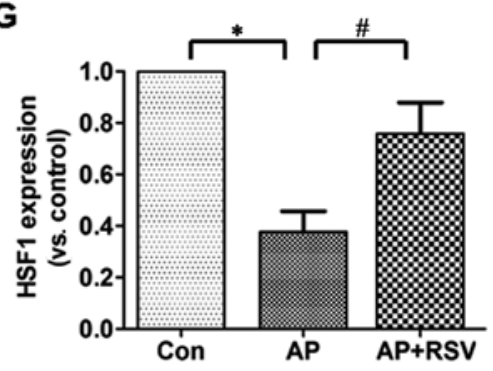

H

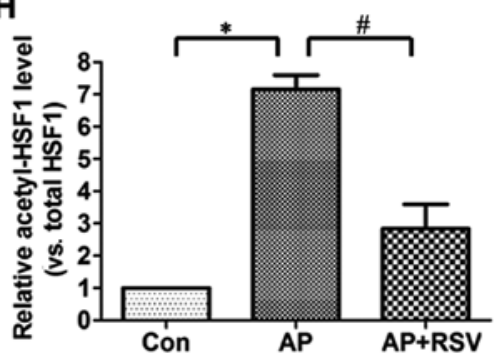

Figure 8. Effect of resveratrol on the expression and acetylation of heat shock factor 1 (HSF1) in the pancreas of mice with L-arginine-induced acute necrotizing pancreatitis (ANP). Interaction between sirtuin 1 (SIRT1) and HSF1 in the pancreas was detected by co-immunoprecipitation at $48 \mathrm{~h}$ (A) and $72 \mathrm{~h}$ (E) after the second injection of L-arginine. Expression of HSF1 and acetylated HSF1 in the pancreas was detected by immunoblotting at $48 \mathrm{~h}(\mathrm{~B}-\mathrm{D})$ and $72 \mathrm{~h}(\mathrm{~F}-\mathrm{H})$ after the second injection of L-arginine. ${ }^{\mathrm{p}} \mathrm{p}<0$. vs. Con; ${ }^{*} \mathrm{p}<0.05$ vs. acute pancreatitis (AP) (n=3). Con, control group; AP, L-arginine exposure group; AP+RSV, L-arginine and resveratrol treatment group.

of its downstream targets mainly through deacetylating the lysine residues at certain sites. p53 has been identified as a downstream target of SIRT1 and the deacetylation level of p53 was proven to be able to indirectly reflect the activity of SIRT1. In this study, the results showed that p53 interacted with SIRT1 in the different experimental groups, the p53 expression was downregulated while the ratio of acetylated p53 was upregulated in the L-arginine-induced mice with ANP, suggesting that the SIRT1 activity was significantly decreased in the mice with ANP, while resveratrol could enhance the SIRT1 activity in the mice with ANP. SIRT1 deacetylates p53 and activates itself to trigger cell apoptosis $(16,17)$ while p53 has been proven to play an important role in the apoptosis of pancreatic acinar cells (23). It seemed to be contradictory that resveratrol activiated SIRT1 and subsequently promoted p53-mediated apoptosis of pancreatic acinar cells by increasing the deacetylation of p53. Actually, studies increasingly suggested that the promotion of apoptosis of pancreatic acinar cells was beneficial to ameliorate ANP because of the decreasing necrosis and severity of the pancreatitis (24-26). Therefore, we speculated that the protective effect of resveratrol on ANP might also be related to the enhancement of SIRT1 activation and subsequent promotion of pancreatic acinar cell apoptosis mediated by p53 deacetylation, while resveratrol eventually decreased the apoptosis of pancreatic acinar cells through other anti-apoptotic mechanisms $(27,28)$.

Inflammatory response persists in the occurrence and development of ANP which is described as progression from an initial injury of pancreatic acinar cells to local and systemic inflammation. HSF1, an important heat shock 
transcription factor, is widely expressed in various types of cells and plays an important role in inflammation by regulating the transcription of inflammatory factors (29-31). The acetylation of HSF1 decreases its DNA binding activity, and thus promotes the transcription of pro-inflammatory factors and inhibits the transcription of anti-inflammatory factors. In our previous study, HSF1-knockout mice developed more severe acute edema pancreatitis induced by cerulein than the wild-type mice. However, the role of HSF1 in ANP is poorly understood. Our results showed that HSF1 expression was significantly decreased in the pancreatic tissues of mice with ANP, indicating that HSF1 is involved in the pathogenesis of ANP. It is particularly noteworthy that HSF1 is a deacetylase substrate for SIRT1 $(10,32)$. Ghemrawi et al found that a decrease in the cellular availability of B12 led to ER stress activation mediated by decreased SIRT1 expression, which in turn led to both lower HSF1 expression and HSF1 hyperacetylation (10). Similarly, in our study, although the total HSF1 expression was decreased in the pancreatic tissue of the L-arginine-induced mice with ANP, the ratio of acetylated HSF1 was sharply increased up to 6- to 8-fold of the normal mice, which may consequently increase the transcription of pro-inflammatory factors (TNF- $\alpha$ and IL-6) but decrease the transcription of anti-inflammatory factors (IL-10). However, resveratrol did not only markedly enhance the total expression of HSF1, but also diminished acetylated HSF1. These results suggest that resveratrol enhances the deacetylation of HSF1 in the pancreas of ANP, and subsequently exhibits its potent anti-inflammatory effect and eventually ameliorates ANP by mediating the transcription of inflammatory factors.

In addition to the deacetylation of p53 and HSF1, other intracellular target proteins and signaling pathways may also be involved in the protective effect of SIRT1 activation on ANP. For instance, nuclear factor- $\kappa \mathrm{B}$ (NF- $\kappa \mathrm{B})$, forkhead box protein (Fox)O1, FoxO3 and FoxO4 are also the deacetylation targets of SIRT1 $(33,34)$. Sirt1 inhibits apoptosis and inflammation via deacetylating these proteins and thereby modulating their activities, which may also contribute to the protective effect of resveratrol on ANP. Mammalian target of rapamycin (mTOR), an important target of SIRT1, inhibits autophagy and has been implicated in the development of pancreatitis $(35,36)$. SIRT1 influences different pathophysiological processes including metabolism, cell apoptosis and aging by downregulating mTOR (37-39). Interestingly, resveratrol exhibited a protective effect on various diseases via the upregulation of mTOR and autophagy. Therefore, the protective effect of resveratrol on ANP may also be attributed to the SIRT1 mTOR axis-enhanced autophagy in the pancreatic acinar cells. Furthermore, the Toll-like receptor 4 (TLR4)/NF- $\kappa B$ pathway mediates the production of various pro-inflammatory factors and has been found to play important roles in the development of panceatitis, whereas resveratrol was found to relieve the inflammatory injury by inhibiting the TLR4/NF-kB pathway $(45,46)$. Hence, the inhibition of the TLR4/NF- $\mathrm{KB}$ pathway may also contribute to the protective effect of resveratrol on ANP.

In conclusion, to the best of our knowledege, our data demonstrated for the first time that resveratrol effectively improved the survival, relieved the inflammatory response and decreased the acinar necrosis and apoptosis in L-arginine- induced ANP in mice, which may be related to the enhancement of SIRT1-mediated deacetylation of p53 and HSF1. Notably, the increase in SIRT1-mediated deacetylation of p53 can promote the apoptosis of pancreatic acinar cells, which might further decrease the necrosis of pancreatic acinar cells and relieve ANP. This may be another important protective effect of resveratrol besides its anti-inflammatory activity.

\section{Acknowledgements}

This study was supported by the National Natural Science Foundation of China (nos. 81000846, 81270201 and 81470408) and the Natural Science Foundation of Hunan Province of China (no. 12JJ4084).

\section{References}

1. Weitz G, Woitalla J, Wellhöner P, Schmidt K, Büning $J$ and Fellermann K: Does etiology of acute pancreatitis matter? A review of 391 consecutive episodes. JOP 16: 171-175, 2015.

2. Agarwal S, George J, Padhan RK, Vadiraja PK, Behera S, Hasan A, Dhingra R, Shalimar and Garg PK: Reduction in mortality in severe acute pancreatitis: A time trend analysis over 16 years. Pancreatology 16: 194-199, 2016.

3. Dellinger EP, Forsmark CE, Layer P, Lévy P, Maraví-Poma E, Petrov MS, Shimosegawa T, Siriwardena AK, Uomo G, Whitcomb DC, et al; Pancreatitis Across Nations Clinical Research and Education Alliance (PANCREA): Determinant-based classification of acute pancreatitis severity: An international multidisciplinary consultation. Ann Surg 256: 875-880, 2012.

4. Sandakov PIa, Samartsev VA and Mineev DA: Surgical and therapeutic treatment of acute pancreatitis. Khirurgiia (Mosk) 10: 56-63, 2014 (In Russian).

5. Hegyi P, Pandol S, Venglovecz V and Rakonczay Z Jr: The acinar-ductal tango in the pathogenesis of acute pancreatitis. Gut 60: 544-552, 2011.

6. Bhatia M: Inflammatory response on the pancreatic acinar cell injury. Scand J Surg 94: 97-102, 2005.

7. Lv JC, Wang G, Pan SH, Bai XW and Sun B: Lycopene protects pancreatic acinar cells against severe acute pancreatitis by abating the oxidative stress through JNK pathway. Free Radic Res 49: 151-163, 2015.

8. Carrasco C, Holguín-Arévalo MS, Martín-Partido G Rodríguez $\mathrm{AB}$ and Pariente JA: Chemopreventive effects of resveratrol in a rat model of cerulein-induced acute pancreatitis. Mol Cell Biochem 387: 217-225, 2014.

9. Sha H, Ma Q, Jha RK, Wu Z, Qingyuan Z, Wang Z, Ma Z, Luo X and Liu C: Resveratrol suppresses microcirculatory disturbance in a rat model of severe acute pancreatitis. Cell Biochem Biophys 67: 1059-1065, 2013.

10. Ghemrawi R, Pooya S, Lorentz S, Gauchotte G, Arnold C, Gueant JL and Battaglia-Hsu SF: Decreased vitamin B12 availability induces ER stress through impaired SIRT1-deacetylation of HSF1. Cell Death Dis 4: e553, 2013.

11. Lee JT and Gu W: SIRT1: Regulator of p53 Deacetylation. Genes Cancer 4: 112-117, 2013

12. Sun C, Zhang F, Ge X, Yan T, Chen X, Shi X and Zhai Q: SIRT1 improves insulin sensitivity under insulin-resistant conditions by repressing PTP1B. Cell Metab 6: 307-319, 2007.

13. Grewal HP, Mohey EDA, Gaber L, Kotb M and Gaber AO: Amelioration of the physiologic and biochemical changes of acute pancreatitis using an anti-TNF-alpha polyclonal antibody. Am J Surg 167: 214-219, 1994.

14. Dawra R, Sharif R, Phillips P, Dudeja V, Dhaulakhandi D and Saluja AK: Development of a new mouse model of acute pancreatitis induced by administration of L-arginine. Am J Physiol Gastrointest Liver Physiol 292: G1009-G1018, 2007.

15. Kui B, Balla Z, Vasas B, Végh ET, Pallagi P, Kormányos ES, Venglovecz V, Iványi B, Takács T, Hegyi P, et al: New insights into the methodology of L-arginine-induced acute pancreatitis. PLoS One 10: e0117588, 2015.

16. Hong W, Tatsuo S, Shou-Dong W, Qian Z, Jian-Feng H, Jue W, Chen J, Hai-Yan Q and Yue-Jin Y: Resveratrol Upregulates Cardiac SDF-1 in mice with acute myocardial infarction through the deacetylation of cardiac p53. PLoS One 10: e0128978, 2015. 
17. Kume S, Haneda M, Kanasaki K, Sugimoto T, Araki S, Isono M, Isshiki K, Uzu T, Kashiwagi A and Koya D: Silent information regulator 2 (SIRT1) attenuates oxidative stress-induced mesangial cell apoptosis via p53 deacetylation. Free Radic Biol Med 40: 2175-2182, 2006.

18. Lankisch PG, Apte $M$ and Banks PA: Acute pancreatitis. Lancet 386: 85-96, 2015.

19. Mayer J, Rau B, Gansauge F and Beger HG: Inflammatory mediators in human acute pancreatitis: Clinical and pathophysiological implications. Gut 47: 546-552, 2000.

20. Vandenabeele P, Galluzzi L, Vanden Berghe T and Kroemer G: Molecular mechanisms of necroptosis: An ordered cellular explosion. Nat Rev Mol Cell Biol 11: 700-714, 2010.

21. Capurso G, Zerboni G, Signoretti M, Valente R, Stigliano S, Piciucchi M and Delle Fave G: Role of the gut barrier in acute pancreatitis. J Clin Gastroenterol 46 (Suppl): S46-S51, 2012.

22. Tani S, Itoh H, Okabayashi Y, Nakamura T, Fujii M, Fujisawa T, Koide $\mathrm{M}$ and Otsuki M: New model of acute necrotizing pancreatitis induced by excessive doses of arginine in rats. Dig Dis Sci 35: 367-374, 1990.

23. Chen J, Chen J, Wang X, Wang C, Cao W, Zhao Y, Zhang B, Cui M, Shi Q and Zhang G: Ligustrazine alleviates acute pancreatitis by accelerating acinar cell apoptosis at early phase via the suppression of p38 and Erk MAPK pathways. Biomed Pharmacother 82: 1-7, 2016.

24. Nakamura Y, Do JH, Yuan J, Odinokova IV, Mareninova O, Gukovskaya AS and Pandol SJ: Inflammatory cells regulate p53 and caspases in acute pancreatitis. Am J Physiol Gastrointest Liver Physiol 298: G92-G100, 2010.

25. Mareninova OA, Sung KF, Hong P, Lugea A, Pandol SJ, Gukovsky I and Gukovskaya AS: Cell death in pancreatitis: Caspases protect from necrotizing pancreatitis. J Biol Chem 281: 3370-3381, 2006.

26. Liu Y, Yuan J, Tan T, Jia W, Lugea A, Mareninova O, Waldron RT and Pandol SJ: Genetic inhibition of protein kinase $\mathrm{C} \varepsilon$ attenuates necrosis in experimental pancreatitis. Am J Physiol Gastrointest Liver Physiol 307: G550-G563, 2014.

27. Gu J, Hu W and Zhang DD: Resveratrol, a polyphenol phytoalexin, protects against doxorubicin-induced cardiotoxicity. J Cell Mol Med 19: 2324-2328, 2015.

28. Han G, Xia J, Gao J, Inagaki Y, Tang W and Kokudo N: Anti-tumor effects and cellular mechanisms of resveratrol. Drug Discov Ther 9: 1-12, 2015.

29. Zhang H, Zhang L, Yu F, Liu Y, Liang Q, Deng G, Chen G, Liu M and Xiao X: HSF1 is a transcriptional activator of IL-10 gene expression in RAW264.7 macrophages. Inflammation 35 : $1558-1566,2012$

30. Chen S, Zuo X, Yang M, Lu H, Wang N, Wang K, Tu Z, Chen G, Liu M, Liu K, et al: Severe multiple organ injury in HSF1 knockout mice induced by lipopolysaccharide is associated with an increase in neutrophil infiltration and surface expression of adhesion molecules. J Leukoc Biol 92: 851-857, 2012.

31. Tong Z, Jiang B, Zhang L, Liu Y, Gao M, Jiang Y, Li Y, Lu Q, Yao Y and Xiao X: HSF-1 is involved in attenuating the release of inflammatory cytokines induced by LPS through regulating autophagy. Shock 41: 449-453, 2014.

32. Raynes R, Pombier KM, Nguyen K, Brunquell J, Mendez JE and Westerheide SD: The SIRT1 modulators AROS and DBC regulate HSF1 activity and the heat shock response. PLoS One 8: e54364, 2013.
33. Kim HN, Han L, Iyer S, de Cabo R, Zhao H, O'Brien CA, Manolagas SC and Almeida M: Sirtuin1 suppresses osteoclastogenesis by deacetylating FoxOs. Mol Endocrinol 29: 1498-1509, 2015.

34. Shinozaki S, Chang K, Sakai M, Shimizu N, Yamada M, Tanaka T, Nakazawa H, Ichinose F, Yamada Y, Ishigami A, et al: Inflammatory stimuli induce inhibitory S-nitrosylation of the deacetylase SIRT1 to increase acetylation and activation of p53 and p65. Sci Signal 7: ra106, 2014.

35. Hu YY, Zhou CH, Dou WH, Tang W, Hu CY, Hu DM, Feng H, Wang JZ, Qian MJ, Cheng GL, et al: Improved autophagic flux is correlated with mTOR activation in the later recovery stage of experimental acute pancreatitis. Pancreatology 15: 470-477, 2015.

36. Ji L, Li L, Qu F, Zhang G, Wang Y, Bai X, Pan S, Xue D, Wang G and Sun B: Hydrogen sulphide exacerbates acute pancreatitis by over-activating autophagy via AMPK/mTOR pathway. J Cell Mol Med 20: 2349-2361, 2016.

37. Kwon HS and Ott M: The ups and downs of SIRT1. Trends Biochem Sci 33: 517-525, 2008

38. Ghosh HS, McBurney M and Robbins PD: SIRT1 negatively regulates the mammalian target of rapamycin. PLoS One 5: e9199, 2010.

39. Zhou XL, Xu JJ, Ni YH, Chen XC, Zhang HX, Zhang XM, Liu WJ, Luo LL and Fu YC: SIRT1 activator (SRT1720) improves the follicle reserve and prolongs the ovarian lifespan of diet-induced obesity in female mice via activating SIRT1 and suppressing mTOR signaling. J Ovarian Res 7: 97, 2014.

40. Diaz-Gerevini GT, Repossi G, Dain A, Tarres MC, Das UN and Eynard AR: Beneficial action of resveratrol: How and why? Nutrition 32: 174-178, 2016.

41. Jung MJ, Lee J, Shin NR, Kim MS, Hyun DW, Yun JH, Kim PS, Whon TW and Bae JW: Chronic repression of mTOR complex 2 induces changes in the gut microbiota of diet-induced obese mice. Sci Rep 6: 30887, 2016.

42. Alayev A, Berger SM and Holz MK: Resveratrol as a novel treatment for diseases with mTOR pathway hyperactivation. Ann NY Acad Sci 1348: 116-123, 2015.

43. Gu J, Hu W, Song ZP, Chen YG, Zhang DD and Wang CQ: Resveratrol-induced autophagy promotes survival and attenuates doxorubicin-induced cardiotoxicity. Int Immunopharmacol 32: 1-7, 2016.

44. Park D, Jeong H, Lee MN, Koh A, Kwon O, Yang YR, Noh J, Suh PG, Park H and Ryu SH: Resveratrol induces autophagy by directly inhibiting mTOR through ATP competition. Sci Rep 6: 21772, 2016.

45. Zhang Z, Chen N, Liu JB, Wu JB, Zhang J, Zhang Y and Jiang X: Protective effect of resveratrol against acute lung injury induced by lipopolysaccharide via inhibiting the myd88-dependent Toll-like receptor 4 signaling pathway. Mol Med Rep 10: 101-106, 2014.

46. Zhong K: Curcumin mediates a protective effect via TLR-4/NF- $\kappa B$ signaling pathway in rat model of severe acute pancreatitis. Cell Biochem Biophys 73: 175-180, 2015. 